Supporting Information

Impregnated Active Carbons to Control Atmospheric Emissions -

Influence of the Raw Material on the Catalytic Activity

MARIA C. M. ALVIM-FERRAZ AND CARLA M. T. B. GASPAR

Environmental Science and Technology 


\section{Impregnation procedure}

For both series of samples, i.e. XCAI and XCIA, the deposition of $\mathrm{CoO}$ was performed by impregnation with cobalt nitrate solutions prepared with $\mathrm{Co}\left(\mathrm{NO}_{3}\right)_{2} \cdot 6 \mathrm{H}_{2} \mathrm{O}$. For the CAI series, a solution volume of $0.6 \mathrm{~cm}^{3}$ was used to impregnate each gram of activated carbon. In order to obtain impregnated active carbons with two different metal contents, solutions with cobalt concentrations of 25.9 and $52.1 \mathrm{~g} \mathrm{dm}^{-3}$ were used, leading, respectively, to final cobalt loadings of 1.5 and $3.0 \%$. For the CIA series, the carbonized material to be impregnated had a porous volume significantly lower than that of activated carbons impregnated in CAI series. Therefore, to get similar cobalt load in both series lower volumes of more concentrated solutions were used. To obtain a final cobalt load of 1.5 and $3.0 \%, 0.06$ and $0.12 \mathrm{~cm}^{3}$ of a cobalt solution with a concentration of $183 \mathrm{~g} \mathrm{dm}^{-3}$ were added to each gram of carbonized material.

The deposition of $\mathrm{Co}_{3} \mathrm{O}_{4}$ (only performed for the XCIA series) was conducted by adding $0.71 \mathrm{~cm}^{3}$ of cobaltous acetate solution $\left(42.6 \mathrm{~g} \mathrm{dm}^{-3}\right.$ in cobalt) to each gram of the carbonized material. To precipitate the cobaltous carbonate, a solution of sodium carbonate in a ratio of 1:5 was then used. After washing with distilled water and drying under vacuum at $333 \mathrm{~K}$, the carbonate was decomposed to $\mathrm{Co}_{3} \mathrm{O}_{4}$ in air at $528 \mathrm{~K}$ (1).

The deposition of $\mathrm{CrO}_{3}$ (only performed for the XCIA series) was carried out by impregnating each gram of carbonized material with $0.12 \mathrm{~cm}^{3}$ of an ammoniacal solution 1:1, containing $0.0800 \mathrm{~g}$ of $(\mathrm{NH} 4)_{2} \mathrm{CO}_{3}$ and $0.0408 \mathrm{~g}$ of $\mathrm{CrO}_{3}$.

\section{Textural Characterization}

Nitrogen adsorption isotherms at $77 \mathrm{~K}$ were used to evaluate the textural parameters of the carbons. Measurements were conducted in a Micromeritics 2700 flow sorptomer. The samples were first outgassed at $473 \mathrm{~K}$ for $15 \mathrm{~h}$ and then weighted. The results were 
expressed in relation to the unit mass of outgassed carbon. The true adsorption equilibrium was guaranteed by checking the adsorption at regular intervals and following it over long periods of time. All isotherms were repeated at least once to obtain reproducible results. BET theory was used as a reference method for calculating the total specific surface areas $\left(S_{\mathrm{BET}}\right)$ of the carbons. The t-method was used for calculation of the non-microporous specific surface areas associated with mesopores $\left(S_{\mathrm{t}}^{\prime}\right)$. The micropore volume $\left(V_{\mathrm{mi}}\right)$ was calculated using the Dubinin-Astakhov equation applied to the micropore adsorption whenever the Dubinin-Radushkevich equation could not be applied. The mesopore volume $\left(V_{\mathrm{me}}\right)$ was obtained by deducting the micropore volume from the volume adsorbed at a relative pressure of 0.95 (2).

\section{Determination of Surface Functional Groups}

Acid and basic functional groups were determined using the Boehm method, involving a selective neutralization analysis (3). Solutions of $\mathrm{NaHCO}_{3}, \mathrm{Na}_{2} \mathrm{CO}_{3}, \mathrm{NaOH}$, and $\mathrm{HCl}$ were prepared using deionized water. Samples of $200 \mathrm{mg}$ of activated carbon and $20 \mathrm{~mL}$ of each solution were shaken (blanks were prepared without carbon). After reaching equilibrium the solutions were separated from the carbons by decanting. The excess of base or acid was determined by back-titration with hydrochloric acid and two solutions of sodium hydroxide with different concentrations.

\section{Chromatographic reactor}

The differential detectors produce signals proportional to solute gas phase concentration, recording chromatographic peaks whose areas are proportional to the weight of solute passing the detector. Therefore, for chromatographic reactors, the total weights of reactant entering and leaving the column $\left(W_{\text {in }}\right.$ and $\left.W_{\text {out }}\right)$ are, respectively, 
proportional to the reactant peak areas without and with chemical reaction $\left(A^{0}{ }_{R}\right.$ and $\left.A_{R}\right)$. If these reactant peak areas are measured with the same detector sensitivity, the reactant conversion $\left(X_{R}\right)$ can be determined at each temperature through the following equation:

$$
X_{R}=1-\frac{A_{R}}{A^{0}{ }_{R}}
$$

For first-order catalytic reactions associated with linear adsorption isotherms on the catalyst support, the continuous flow model for ideal chromatographic reactors relates $W_{\text {in }}, W_{\text {out }}$, the velocity constants in gaseous and solid phases $\left(k_{g}\right.$ and $\left.k_{s}\right)$, and the residence time in gaseous and solid phases $\left(t_{g}\right.$ and $\left.t_{s}\right)$ :

$$
\frac{W_{\text {in }}}{W_{\text {out }}}=\frac{A_{R}}{A^{0}{ }_{R}}=\exp \left(k_{g} t_{g}+k_{s} t_{s}\right)
$$

Defining the apparent rate constant, $k_{a p}$, equations [1] and [2] are transformed in equation [4]:

$$
\begin{gathered}
k_{a p}=k_{s}+k_{g} \frac{t_{g}}{t_{s}} \\
-\ln \left(1-X_{R}\right)=-\ln \frac{A_{R}}{A^{0}{ }_{R}}=k_{a p} t_{s}
\end{gathered}
$$

Sometimes $k_{s}$ and $k_{g}$ can both be independently evaluated. Nevertheless, it frequently happens that $k_{s}$ value is at least one order of magnitude greater than $k_{g}$, being $t_{g} / t_{\mathrm{s}}$ less than 0.2 . In this case, it is not possible to evaluate independently $k_{s}$ and $k_{g}$, being $k_{a p}$ approximately equal to $k_{s}$. Then, $X_{R}$ can be related to the residence time in the solid phase through the following equation: 


$$
-\ln \left(1-X_{R}\right)=-\ln \frac{A_{R}}{A^{0}{ }_{R}}=k_{s} t_{s}
$$

At each temperature, $k_{s}\left(\mathrm{~s}^{-1}\right)$ can be calculated through the experimental values of $A_{R}$, $A_{R}^{0}$ and $t_{s}$, determined through chromatograms obtained at different flow rates, and plotting $\ln \left(A_{R} / A^{0}{ }_{R}\right)$ against $t_{s}$, where the slope is (- $\left.k_{s}\right)(4-7)$.

The reactant peak areas without chemical reaction $\left(A_{R}^{0}\right)$ were determined in parallel using a column filled with a non-impregnated carbon. In order to confirm that no chemical reaction exists with the non-impregnated carbon, the stability of the $A_{R}^{0}$ values was evaluated by lowering the column temperature (the sensitivity of the flame ionization detector is not affected by column temperature in the range considered). As the sensitivity depends on the carrier gas flow rate, $A_{R}^{0}$ was determined for all the flow rates used. These values were also compared with those obtained with the columns filled with the impregnated carbons at temperatures at which no reaction can occur. The observed results showed good agreement.

The residence time in solid phase $\left(t_{s}\right)$ was calculated by subtracting the residence time in gaseous phase $\left(t_{g}\right)$ from the global chromatographic retention time measured in the chromatograms.

The residence time in gaseous phase corresponds to the chromatographic retention time of a non-adsorbed gas. It was determined experimentally by injecting helium into a chromatograph fitted with a thermal conductivity detector. These values were compared with the ones calculated using porosity parameters, column volume and flow rate. Good agreement was noted, and $t_{g} / t_{s}$ was always smaller than 0.1 . Therefore, considering that $k_{s}$ value is much higher than $k_{g}$, equation [5] can be used for the calculation of $k_{s}$. 
When a linear adsorption isotherm on a solid is observed, the adsorption equilibrium constant $(K)$ can be related to the residence time in the solid phase, the carrier gas flow rate corrected to column temperature and pressure $(U)$, and the weight of solid phase (m) (6):

$$
K=\frac{t_{s} U}{m}
$$

\section{Literature cited}

(1) Alvim-Ferraz, M. C. M; Gaspar, C. M. T. B. J. Porous Mat. 2003, 10, 47-55.

(2) Alvim-Ferraz, M. C. M.; Gaspar, C. M. T. B. J. Colloid Interface Sci. 2003, 266, 160-167.

(3) Valdés, H.; Sánchez-Polo, M.; Rivera-Utrilla J.; Zaror C.A. Langmuir 2002, 18, 2111-2116.

(4) Kokes, R. J.; Tobin Jr, H.; Emmett, P. H. J. Amer. Chem. Soc. 1955, 77, 58605862.

(5) Langer, S. H.; Yurchack, J. Y.; Patton, J. E. Ind. Eng. Chem. 1969, 61, 11-21.

(6) Langer, S. H.; Patton, J. E. Chemical reactor applications of the gas chromatographic column. In New development in gas chromatography; John Wiley: New York, 1974; pp 293-373.

(7) Alvim-Ferraz, M. C. M. Preparação de Carvões Activados Impregnados, PhD Thesis; Faculdade de Engenharia da Universidade do Porto: Porto, 1983; pp 165205. 